\title{
Preparation and Purification of Some Oxidation Products of Perylene
}

\author{
Alexander J. Fatiadi \\ Institute for Materials Research, National Bureau of Standards, Washington, D.C. 20234
}

(August 17, 1967)

\begin{abstract}
Reliable procedures are given for the purification of perylene, and for the preparation and purification of 3,10-perylenequinone, 1,12-perylenequinone, 2,11-dihydroxy-3,10-perylenequinone, 4,9-dihydroxy3,10-perylenequinone, 4-oxo-4H-benz[de]anthracene-7,8-dicarboxylic anhydride, phenanthrene $1,8,9,10$ tetracarboxylic dianhydride, and anthraquinone-1,5-dicarboxylic acid. Data on the physical properties of 3,9-perylenequinone are also reported.

Key Words: Absorption spectra, air pollutants, anthraquinone-1,5-dicarboxylic acid, dihydroxyperylenequinones, infrared, 4-oxy-4H-benz|de]anthracene-7,8-dicarboxylic anhydride, perylene, perylenequinones, photo-oxidation products of pervlene, polycvelic aromatic hydrocarbons, thin-layer chromatograms, ultraviolet, visible absorption spectra.
\end{abstract}

\section{Purpose and Scope of the Project}

Pure reference compounds derived from perylene, particularly various oxidation products, were needed in connection with a study of the products resulting from photochemical reactions of perylene adsorbed on various particulates. Because these compounds were not available in a suitable state of purity, the methods reported in the experimental part were developed for their synthesis and purification. Reliable procedures are given for the purification of perylene (1), and for the preparation and purification of 3,10-perylenequinone (2), 1,12-perylenequinone (3), 2,11-dihydroxy3,10-perylenequinone (4), 4,9-dihydroxy-3,10-perylenequinone (5), 4-oxo-4H-benz[ de] anthracene-7-8-dicarboxylic anhydride (6), phenanthrene-1,8,9,10-tetracarboxylic dianhydride (7), and anthraquinone-1,5-dicarboxylic acid (8). The preparation of 3,9-perylenequinone (9) is also reported.

The purification of the compounds was followed by thin-layer chromatography until constant, reproducible $R_{f}$ values were obtained. For identification purposes, the infrared absorption spectra of compounds $\mathbf{1}$ to $\mathbf{8}$ were recorded; these are reproduced in figure 1 . The peaks in the ultraviolet and visible spectra of these compounds are given in table 1.

${ }^{1}$ Figures in brackets indicate the literature references at the end of this paper.

${ }^{2}$ Certain commercial products and instruments are identified in this paper in order to specify adequately the experimental procedure. In no case does such identification imply recommendation or endorsement by the National Bureau of Standards, nor does it imply that the products or equipment identified are necessarily the best available for the purpose.

\section{Purification of Perylene (1)}

A solution of $300 \mathrm{mg}$ (0.0012 mole) of perylene (commercial grade) in 1:1 (v/v) benzene-toluene (50 $\mathrm{ml})$ was introduced onto a column $(3.5 \times 50 \mathrm{~cm})$ of silica gel (100-200 mesh), and the column was eluted with $3: 1(\mathrm{v} / \mathrm{v})$ glacial acetic acid-benzene. A small, fore-running zone was discarded; a major yellow zone, which sometimes had a grayish purple shade, was collected and concentrated to dryness. Recrystallization from glacial acetic acid, and then from xylene, yielded lustrous yellow-orange plates; yield $250 \mathrm{mg}$ (83\%), mp 275 to $277^{\circ} \mathrm{C}$. A sample sublimed at $20{ }^{\circ} \mathrm{C} /$ $0.05 \mathrm{~mm}$ had mp 276 to $278{ }^{\circ} \mathrm{C}$; lit. mp 264 to $265^{\circ} \mathrm{C}$ [1], ${ }^{1} 273$ to $274{ }^{\circ} \mathrm{C}$ [2].

A thin-layer chromatogram $(5 \times 20 \mathrm{~cm}$ glass plate covered with freshly activated Silica Gel G, $250 \mu \mathrm{m}$ thick), showed a homogeneous yellow spot that had a blue fluorescence; 2:1:1 (v/v) heptane-toluene-acetic acid (solvent A), $60 \mathrm{~min}$, gave $R_{f} 0.88 \pm 0.01 ; 18: 1: 1$ (v/v) heptane-toluene-acetic acid, $60 \mathrm{~min}$, gave $R_{f}$ $0.46 \pm 0.01$. If the chromatogram is spotted with a concentrated solution of perylene, two fluorescent areas are usually observed, namely, a yellow spot surrounded by a bluish halo. A thin-layer chromatogram of the purified material was in reasonable agreement with that of a sample of perylene purified by zone-refining.

If the chromatogram is exposed to iodine vapor for 2 $\mathrm{min}$, the color of the spot, originally yellow, turns 

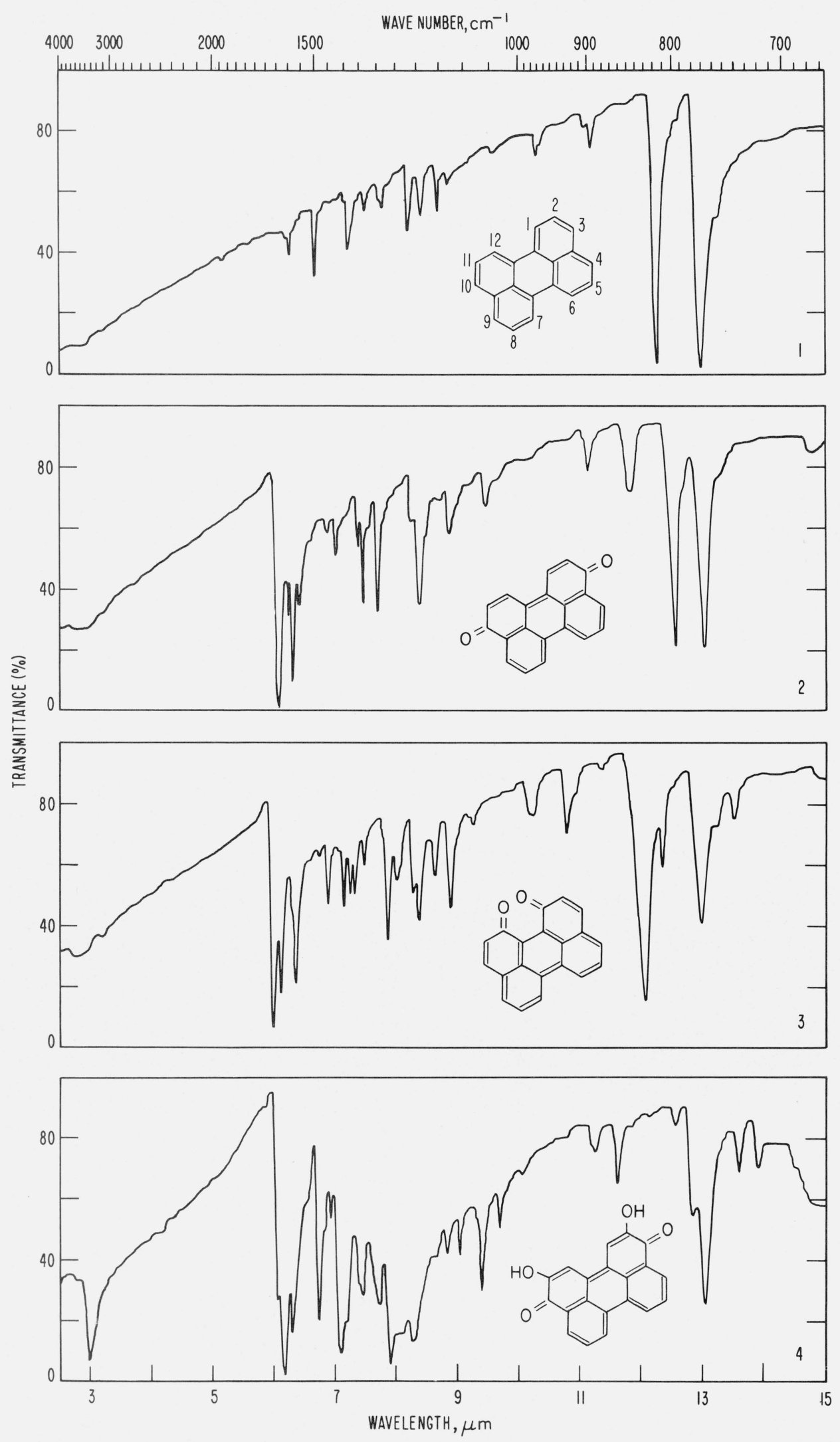

FIGURE 1. Spectrograms of compounds in potassium chloride pellets.

1, Perylene; 2, 3,10-perylenequinone; 3, 1,12-perylenequinone; 4, 2,11-dihydroxy-3,10-perylenequinone. 

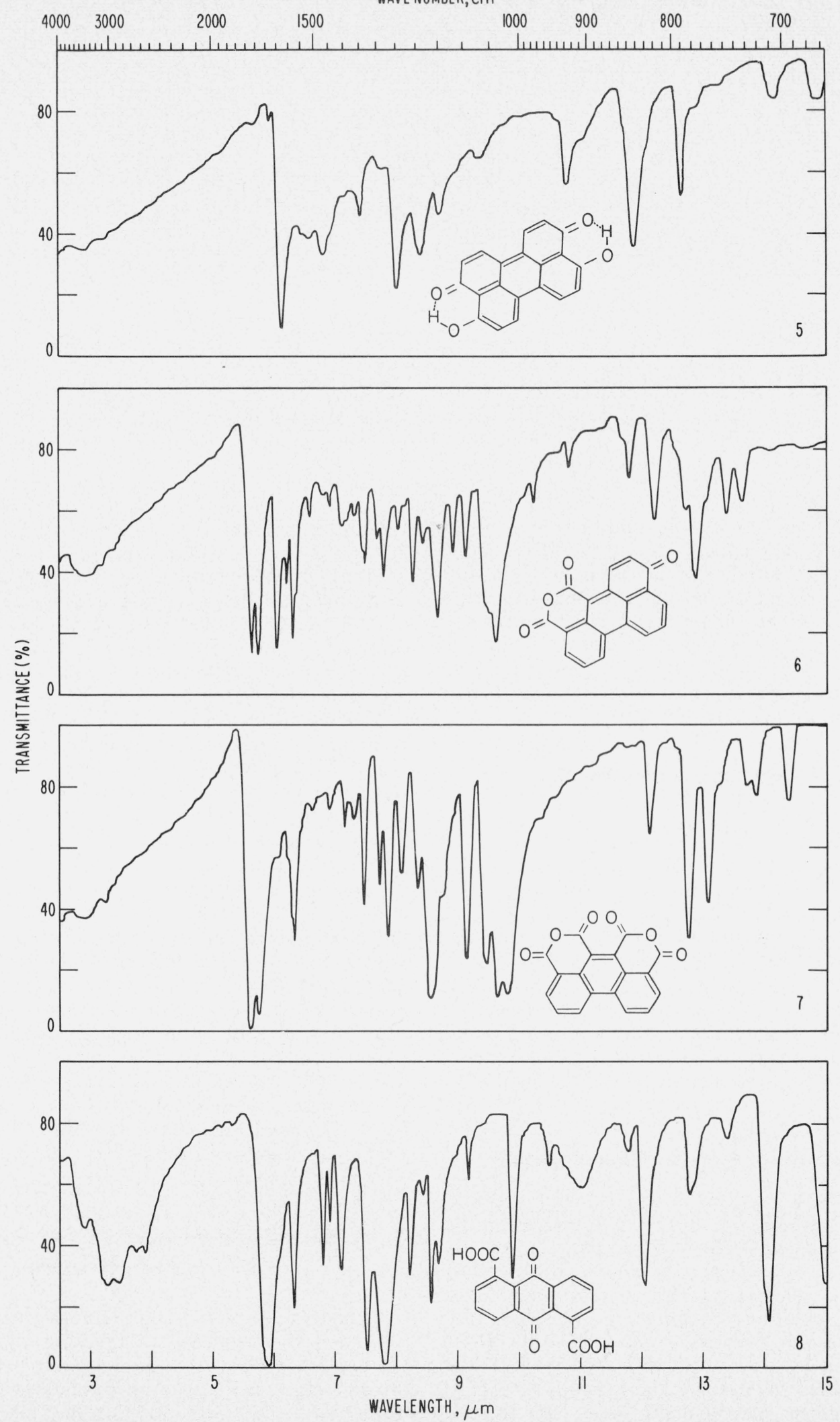

FiguRE 1. Spectrograms of compounds in potassium chloride pellets. - Continued

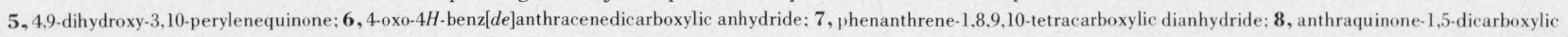
acid. 
TABle 1. Peaks ( $\mathrm{nm}$ ) in ultraviolet and visible spectra ${ }^{\text {a }}$ of compounds $\mathbf{1 - 9}$

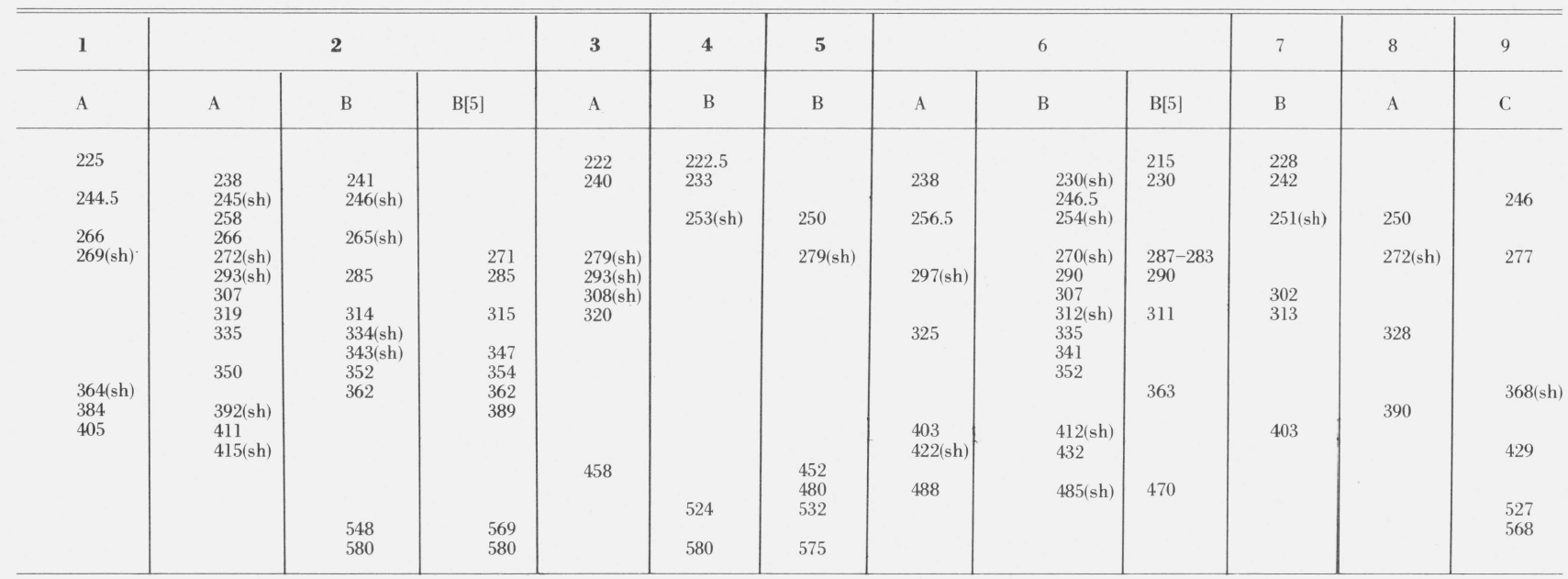

${ }^{a}$ Key to solvents: A, absolute methanol; B, concentrated sulfuric acid; C, chloroform.

olive-brown, and the strong blue fluorescence disappears; this change is probably due to the formation of a charge-transfer complex [3] between perylene and iodine, because, when the spot is reexposed to air, it reacquires its original yellow color and blue fluorescence. This technique is useful in distinguishing between a polycyclic, aromatic hydrocarbon that forms such a complex with iodine vapor and its halogen derivatives (which usually do not).

\section{3,10-Perylenequinone (2)}

\subsection{Discussion}

3,10-Perylenequinone (2) may be prepared by oxidation of perylene with chromic acid according to the method of Zinke and Unterkreuter [4]. Dione 2 is rather difficult to purify by recrystallization. In table 1 , the ultraviolet and visible spectra of dione $\mathbf{2}$ as reported by Brown and Todd [5] are compared with those of the product purified as described in section 3.2.

Analytically pure dione $\mathbf{2}$ has been obtained by two methods of purification: (a) column chromatography on silica gel, and (b) adsorption chromatography on activated carbon.

\subsection{Preparation of 3,10-Perylenequinone (2)}

One gram (0.004 mole) of perylene (reagent grade) was oxidized with chromic acid ( $10 \mathrm{~g}$ of chromium trioxide in $100 \mathrm{ml}$ of water) for $6 \mathrm{hr}$ at $100^{\circ} \mathrm{C}$ with continuous agitation, according to a published procedure [4]. The mixture was filtered while hot, and the filtrate was saved for isolation of compound 8 . The crude product was washed with water, and dried at $50{ }^{\circ} \mathrm{C}$; yellowish brown powder, yield 1.0-1.05 g (89-94\%).

Crude 3,10-perylenequinone ( $150 \mathrm{mg}$ ) was dissolved in $150 \mathrm{ml}$ of warm, glacial acetic acid, the solution was cooled to 35 to $40{ }^{\circ} \mathrm{C}$, and an insoluble residue (25 mg) was filtered off. The dark-brown filtrate was then introduced onto a column of silica gel $(5 \times 50 \mathrm{~cm}$, 100 to 200 mesh), which was eluted with glacial acetic acid by the technique described elsewhere [6]. The fast-moving, light-yellow zone (A), composed primarily of compounds $\mathbf{1}$ and $\mathbf{8}$, was followed by a slow-moving, deep-yellow zone (B), composed of dione 2; the next zone (C) was yellow-brown and mainly contained compound 6.

The deep-yellow zone (B) was collected, and concentrated to dryness; yield of crude 2, 65 to $70 \mathrm{mg}$ (43-47\%); mp 380 to $382{ }^{\circ} \mathrm{C}$ (dec.). The product was purified by dissolving $50 \mathrm{mg}$ in $100 \mathrm{ml}$ of warm, glacial acetic acid, and filtering the solution into a vigorously stirred mixture of $50 \mathrm{ml}$ of warm, glacial acetic acid and $1 \mathrm{~g}$ of Darco activated carbon. (See footnote 2.) Compound $\mathbf{2}$ was quickly adsorbed onto the carbon, and the solution became colorless after the mixture had been stirred for 2 to $3 \mathrm{~min}$. The carbon (containing adsorbed dione) was filtered off, washed with acetic acid, dried at $50{ }^{\circ} \mathrm{C}$, and extracted with $5 \mathrm{ml}$ of warm nitrobenzene. The extract was kept at room temperature for 1 to $2 \mathrm{hr}$; compound 2 crystallized as lightyellow needles; $30 \mathrm{mg}(20 \%)$, mp 390 to $392{ }^{\circ} \mathrm{C}$ (dec.); lit. $\mathrm{mp} 350{ }^{\circ} \mathrm{C}$ [4]. This material produced one sharp, yellow spot having a strong, purple-pink fluorescence on a thin-layer chromatogram with 18:1:1 (v/v) benzene- $N, N$-dimethylformamide-acetic acid (solvent B), $75 \min , R_{f} 0.65 \pm 0.02$.

\section{A Simplified Procedure for Purification of 3,10-Perylenequinone (2)}

Analytically pure 3,10 -perylenequinone is difficult to obtain by fractional recrystallization. However, a product of about 98 percent purity, which can be utilized for many purposes (including oxidation, and reduction to the corresponding diol), may be obtained as follows. A sample of crude 3,10-perylenequinone $(400 \mathrm{mg})$ is successively extracted with benzene in a 
Soxhlet apparatus for $6 \mathrm{hr}$, and then with $150 \mathrm{ml}$ of 4 percent aqueous sodium hydroxide solution by stirring at 40 to $45{ }^{\circ} \mathrm{C}$ for $2 \mathrm{hr}$. The crude dione $\mathbf{2}$ is then successively recrystallized from $4: 1(\mathrm{v} / \mathrm{v}) \quad N, N:-$ dimethylformamide-glacial acetic acid $(50 \mathrm{ml})$ and warm nitrobenzene $(50 \mathrm{ml})$; yield 240 to $260 \mathrm{mg}$ $(60-65 \%)$. This product gives a quite satisfactory thinlayer chromatogram and infrared spectrum; the impurity that shows absorption bands at 5.65 and 5.75 $\mu \mathrm{m}$ is diminished to an amount corresponding to ca. 98 percent purity.

\section{Anthraquinone-1,5-dicarboxylic Acid (8)}

\subsection{Discussion}

Anthraquinone-1,5-dicarboxylic acid (8) [7] may be prepared by oxidation of perylene or 3,10-perylenequinone with chromic acid $[4,8]$; or by oxidation of 3,9-perylenequinone with chromic anhydride in sulfuric acid [9]; it may be characterized as its dimethyl ester [10].

\subsection{Preparation of Anthraquinone-1,5-dicarboxylic Acid (8)}

The dark-brown filtrate obtained after separation of 2 (see sec. 3.2) was kept at room temperature for 48 hr, to yield crude $8,50 \mathrm{mg}(4.8 \%)$. The crude product $(50 \mathrm{mg})$ was dissolved in about $10 \mathrm{ml}$ of 10 percent aqueous ammonium hydroxide, the solution was filtered, and the cold filtrate was acidified with dilute hydrochloric acid. The precipitated acid (8) was further purified by recrystallization from aqueous methanol (with concentration and cooling) to yield colorless or pale-yellow, lustrous crystals of $\mathbf{8}$; yield $35 \mathrm{mg}(3.3 \%)$; mp 388 to $390{ }^{\circ} \mathrm{C}$ (sintering at $340{ }^{\circ} \mathrm{C}$, anhydride formation). A thin-layer chromatogram (silica gel G, $250 \mu \mathrm{m}$ thick) showed a colorless to paleyellow spot having light-blue fluorescence, solvent A, $60 \mathrm{~min}, R_{f} 0.32 \pm 0.02$.

\section{4-Oxo-4H-benz [de]anthracenedicarboxylic Anhydride (6)}

\subsection{Discussion}

4-Oxo-4H-benz $[$ de $]$ anthracenedicarboxylic anhydride (6) ("perylenic acid") may be prepared by exhaustive oxidation of perylene (1) with chromic acid [11, 12], by oxidation of 3,10-perylenequinone $(2)$ with either manganese dioxide in concentrated sulfuric acid [11] or potassium permanganate in pyridine [5], or by oxidation of perylene (1) with hydrogen peroxidevanadium pentaoxide complex as described in sec. 6.3.

\subsection{Preparation of $4-0 \times 0-4 H$-benz $[$ de]anthracenedi- carboxylic Anhydride (6)}

To a stirred solution of crude 3,10-perylenequinone (2) (1 g; 0.0035 mole) in $50 \mathrm{ml}$ of concentrated sulfuric acid (cherry-red solution) at $95{ }^{\circ} \mathrm{C}$ was added, portionwide, $6 \mathrm{~g}$ of active manganese dioxide during $1 \mathrm{hr}$. The brown-red solution was cooled, and poured into ice water $(400 \mathrm{ml})$, and the precipitate was filtered off; yield of crude 6,250 to $300 \mathrm{mg}(23.7-28.4 \%)$. The crude mixture was extracted with $150 \mathrm{ml}$ of warm 4 percent aqueous sodium hydroxide at 45 to $50{ }^{\circ} \mathrm{C}$ for $2 \mathrm{hr}$, and the suspension was filtered. On acidification with dilute hydrochloric acid, the filtrate, which showed a deep-green fluorescence, yielded $200 \mathrm{mg}$ (19\%) of crude 6. The crude acid (6) was dissolved in $150 \mathrm{ml}$ of warm, glacial acetic acid, the solution was filtered, and the filtrate was chromatographed on a column $(5 \times 50 \mathrm{~cm})$ of silica gel with glacial acetic acid as the eluant. The second zone (brown-yellow) was collected, and evaporated to dryness; the product was refluxed with acetic anhydride for $30 \mathrm{~min}$, and the extract was evaporated to dryness. Recrystallization from nitrobenzene-pentane yielded orange-yellow crystals of 8, $60 \mathrm{mg}(5.7 \%), \mathrm{mp} 335$ to $337^{\circ} \mathrm{C}$ (dec.). A thin-layer chromatogram showed a yellow to yellow-orange spot having a light-blue fluorescence; solvent $\mathrm{B}, 60 \mathrm{~min}$, $R_{f} 0.57 \pm 0.02$.

\subsection{Oxidation of Perylene With Hydrogen Peroxide- Vanadium Pentaoxide Complex}

To a solution of perylene (1) $(0.5 \mathrm{~g} ; 0.002$ mole) in $200 \mathrm{ml}$ of glacial acetic acid at $100{ }^{\circ} \mathrm{C}$ was added dropwise, with stirring, the yellow complex prepared by dissolving $100 \mathrm{mg}$ of vanadium pentaoxide in $10 \mathrm{ml}$ of 50 percent hydrogen peroxide; a vigorous reaction ensued, and the solution turned blue-purple. After addition was complete $(10 \mathrm{~min})$, the mixture was stirred at room temperature for $60 \mathrm{~min}$; then $50 \mathrm{ml}$ of water was added, and the mixture was stirred for $15 \mathrm{~min}$, and concentrated to about $50 \mathrm{ml}$. The resulting precipitate $(300 \mathrm{mg})$ was stirred with warm 4 percent aqueous sodium hydroxide for $2 \mathrm{hr}$, and the suspension was filtered; the filtrate was acidified with dilute hydrochloric acid, to give crude $6(200 \mathrm{mg}, 33.9 \%)$. This product was purified by column chromatography on silica gel as described in sec. 6.2 ; the yield of 6 was $95 \mathrm{mg}(16.1 \%)$. A thin-layer chromatogram was identical with that of the product described in sec. 6.2.

\section{Phenanthrene-1,8,9,10-tetracarboxylic Dianhydride (7)}

\subsection{Discussion}

Compound 7 may be prepared by oxidation of compound 6 with nitric acid [12].

Compound 7 was prepared by a modification of the procedure of Brown and Todd [5]. Use of $N, N$-dimethylformamide as a cosolvent in the oxidation enhanced the solubility of the starting material, dione $\mathbf{2}$, and resulted in a higher yield of 7 . 


\subsection{Preparation of Phenanthrene-1,8,9,10- tetracarboxylic Dianhydride (7)}

A mixture of compound 2 (400 mg; 0.0014 mole), finely powdered potassium permangate $(1 \mathrm{~g}), N, N$ dimethylformamide $(50 \mathrm{ml})$, pyridine $(10 \mathrm{ml})$, acetic acid $(5 \mathrm{ml})$, and $3 \mathrm{ml}$ of water was heated at $100{ }^{\circ} \mathrm{C}$ for $30 \mathrm{~min}$, and filtered hot from the precipitate of manganese dioxide. The brownish filtrate was cooled, and a small amount of the starting material separated; this was filtered off, and the filtrate was saved. The manganese dioxide was extracted with $150 \mathrm{ml}$ of 4 percent aqueous sodium hydroxide at $50{ }^{\circ} \mathrm{C}$ for $2 \mathrm{hr}$, and the suspension was filtered. The two filtrates were combined, cooled, acidified with dilute hydrochloric acid, and kept overnight at room temperature, affording crystals that were reextracted with base and reprecipitated from the extract, affording crude dianhydride 7 (80-100 mg) (17.8-22.2\%); this was purified by column chromatography on silica gel. Elution with 9:1 (v/v) glacial acetic acid-2-butanone gave a yellow zone, which was collected, and evaporated to dryness. The product was recrystallized from acetic anhydride $(35 \mathrm{ml})$, to yield pale-yellow to orange-yellow crystals of dianhydride 7 , yield $30 \mathrm{mg}(6.6 \%)$; mp 362 to $364{ }^{\circ} \mathrm{C}$ (dec.). A thin-layer chromatogram on Silica Gel G (250 $\mu \mathrm{m}$ thick) showed a pale-yellow spot having a strong blue-green fluorescence, solvent B, $75 \mathrm{~min}$, $R_{f} 0.22 \pm 0.04$.

\section{2,11-Dihydroxy-3,10-perylenequinone (4)}

\subsection{Discussion}

2,11-Dihydroxy-3,10-perylenequinone was prepared by Friedel-Crafts condensation of 1,2-naphthoquinone by a modification of the procedure of Zinke and coworkers [13].

\subsection{Preparation of 2,11-Dihydroxy-3,10- perylenequinone (4)}

A mixture of finely powdered 1,2-naphthoquinone ( $2 \mathrm{~g})$, sodium chloride ( $2 \mathrm{~g})$, and anhydrous aluminum chloride (15 g) was placed in a round-bottomed flask (protected with a drying tube) and was heated in an oil bath at 140 to $145{ }^{\circ} \mathrm{C}$ for $3 \mathrm{hr}$. The mixture was cooled, cautiously treated with $6 \mathrm{~N}$ hydrochloric acid, and refluxed for 5 to $10 \mathrm{~min}$; the resulting dark-purple solid was filtered off, washed with water, and dried, yield of crude $4,1.89 \mathrm{~g}(94.5 \%)$. The product was recrystallized in the following way: crude product (800 mg) was heated, with stirring, with $280 \mathrm{ml}$ of nitrobenzene, and the suspension was filtered while hot; the product crystallized out on cooling the filtrate. It was redissolved by heating, and the solution was cooled to about $40{ }^{\circ} \mathrm{C}$; the product was filtered off, washed successively with nitrobenzene, benzene, and methanol, and dried in a vacuum desiccator, giving lustrous, green-purple crystals of $\mathbf{4}$; yield $200 \mathrm{mg}$
(25\%), mp 432 to $435{ }^{\circ} \mathrm{C}$ (dec.). The sample was recrystallized once more for analysis.

A thin-layer chromatogram showed a purple-pink spot when the solution was dilute, and a deep-blue spot when the solution was concentrated (weak-purple fluorescence, changing to a blue fluorescence, under ultraviolet light illumination for $2-3 \mathrm{~min}$ ); silica gel $\mathrm{G}$, $200 \mu \mathrm{m}$ thick, 8:1:1 (v/v) toluene- $N, N$-dimethylformamide-acetic acid (solvent C), $8 \mathrm{~min}, R_{f} 0.48 \pm 0.03$.

\section{4,9-Dihydroxy-3,10-perylenequinone (5)}

\subsection{Discussion}

4,9-Dihydroxy-3,10-perylenequinone (5) can be prepared by hydrolysis of 3,4,9,10-tetranitroperylene [14, $15]$, followed by air oxidation of the $3,4,9,10$-perylenetetrol obtained [15].

\subsection{Preparation of 4,9-Dihydroxy-3,10- perylenequinone (5)}

A solution of 3,4,9,10-tetranitroperylene in concentrated sulfuric acid was heated in the air at $140{ }^{\circ} \mathrm{C}$ for $6 \mathrm{hr}[14,15]$. The product was twice recrystallized from nitrobenzene, and then sublimed at $400{ }^{\circ} \mathrm{C} / 0.05$ $\mathrm{mm}$, to give lustrous, blue-black crystals, mp 480 to $485{ }^{\circ} \mathrm{C}$ (with sublimation and some decomposition). A thin-layer chromatogram (silica gel G, $200 \mu \mathrm{m}$ thick) showed an olive-brown spot having a strong, purple fluorescence, relatively stable to short illumination by ultraviolet light; solvent C, $8 \mathrm{~min}, R_{f} 0.63 \pm 0.04$.

\section{1,12-Perylenequinone (3)}

\subsection{Discussion}

1,12-Perylenequinone (3) was prepared by oxidation of crude 1,12-perylenediol with air and then with lead dioxide, following the procedure of Zinke and Hanselmayer [16]. It has been found in this laboratory, however, that the above procedure is not very efficient, as the desired dione (3) is a labile compound that is difficult to prepare in quantity and to purify. Purification of dione $\mathbf{3}$ by fractional recrystallization, as described in reference [16], does not afford a homogeneous product, as is evident from thin-layer chromatograms (see sec. 10.6). The procedure for the purification of dione 3 described here involves two chromatographic separations: (a) on silica gel and (b) on neutral alumina. Dione 3, obtained in very low yield, has been found to have a melting point (215$\left.217{ }^{\circ} \mathrm{C}\right)$ considerably lower than that reported $\left(287^{\circ} \mathrm{C}\right)$ [16]; it gave a satisfactory elementary analysis, and yielded the known [16] 1,12-dibenzoyloxyperylene on reductive benzoylation.

The starting material (1,12-perylenediol) was prepared by a sequence of reactions, including oxidative dimerization of 2-naphthol to $1,1^{\prime}$-bi-2-naphthol, conversion of the latter into the corresponding dimethyl 
ether, and cyclization and demethylation of the ether intermediate to 1,12-perylenediol. The preparation of the reaction intermediates is described in the following subsections.

\subsection{Oxidative Dimerization}

A stirred solution of 2-naphthol (25 g; 1.73 moles) in $400 \mathrm{ml}$ of methanol and $300 \mathrm{ml}$ of water was treated, in portions, with an aqueous solution $(100 \mathrm{ml})$ of ferric chloride hexahydrate ( $50 \mathrm{~g} ; 1.85$ mole) at $55^{\circ} \mathrm{C}$ during 5 to $7 \mathrm{~min}$; stirring was continued for $45 \mathrm{~min}$ at 50 to $52{ }^{\circ} \mathrm{C}$. At this point, the product crystallized out from the green mixture; the mixture was cooled to about $20{ }^{\circ} \mathrm{C}$, and the product was filtered off, washed with ice-cold 3:1:1 (v/v) water-methanol-acetone, and dried in a vacuum oven at $50{ }^{\circ} \mathrm{C}$ for $48 \mathrm{hr}$; yield of the first crop of 1,1'-bi-2-naphthol (white, or slightly palegreenish needles), $14.1 \mathrm{~g}, \mathrm{mp} 205$ to $208{ }^{\circ} \mathrm{C}$. Concentration of the filtrate, and further dilution with water and cooling, yielded a second crop of lower quality (4.2$4.5 \mathrm{~g})$. The product was recrystallized once from water-methanol-acetone (decolorizing carbon), and this product $\left(\mathrm{mp} 212-214{ }^{\circ} \mathrm{C}\right)$ was used in the next step.

An analytical sample was obtained by twice recrystallizing the product from glacial acetic acid, to give snow-white, lustrous crystals; dried at $140{ }^{\circ} \mathrm{C} / 0.05 \mathrm{~mm}$ for $3 \mathrm{hr}, \mathrm{mp} 216$ to $218^{\circ} \mathrm{C}$; the solidified melt had mp 219 to $220{ }^{\circ} \mathrm{C}$; lit. $\mathrm{mp} 218{ }^{\circ} \mathrm{C}$ [17]. Increase in concentration of the ferric chloride, or of the starting material, did not improve the yield of the product, but gave a colored product; the dilute solution seemed to be important for the success of the oxidative dimerization reaction; $\nu_{\max }^{\mathrm{KCl}} 3509(\mathrm{w}) ; 3448(\mathrm{~s}) ; 3058(\mathrm{w}) ; 1624(\mathrm{~s})$; $1592(\mathrm{~s}) ; 1515(\mathrm{~s}) ; 1466(\mathrm{~s}) ; 1435(\mathrm{~m}) ; 1408(\mathrm{sh}) ; 1385(\mathrm{~s})$; $1351(\mathrm{w}) ; 1321(\mathrm{~m}) ; 1279(\mathrm{~m}) ; 1253(\mathrm{~s}) ; 1217(\mathrm{~s}) ; 1174(\mathrm{~s})$; 1144(s); 1124(w); 1070(sh); 1020(w); 982(m); 954(m); 948(sh); 935(m); 868(m); 830(s); 820(sh); 799(sh); $776(\mathrm{~m}) ; 767(\mathrm{~s}) ; 722(\mathrm{~m}) ; 676(\mathrm{~m}) \mathrm{cm}^{-1}$.

\subsection{Methylation}

Once-recrystallized ${ }^{3} \quad$ 1,1'-bi-2-naphthol (mp 210$212{ }^{\circ} \mathrm{C}, 10 \mathrm{~g}$ ) was dissolved, with stirring, in 8 percent aqueous sodium hydroxide $(100 \mathrm{ml})$ containing $2 \mathrm{~g}$ of sodium hydrosulfite; the solution was treated dropwise with methyl sulfate $(15 \mathrm{ml})$ at $55{ }^{\circ} \mathrm{C}$ in a hood; the dimethyl ether crystallized out after 15 to $30 \mathrm{~min}$ of stirring. The reaction mixture was cooled and filtered, and the solid was washed with water, and dried in a vacuum desiccator. The yield of crude $2,2^{\prime}$-dimethoxy$1, l^{\prime}$-binaphthyl was $8.8 \mathrm{~g}(82.8 \%)$. A sample recrystallized from $4: 1(\mathrm{v} / \mathrm{v})$ acetic acid-ethanol and dried at $110{ }^{\circ} \mathrm{C} / 0.05 \mathrm{~mm}$ for $3 \mathrm{hr}$ had $\mathrm{mp} 190$ to $191{ }^{\circ} \mathrm{C}$; lit. $\mathrm{mp} 190{ }^{\circ} \mathrm{C}$ [18]; $\nu_{\max }^{\mathrm{KCl}} 3086(\mathrm{w}) ; 2959(\mathrm{w}) ; 2858(\mathrm{w})$; 1618(s); 1592(s); 1503(s); 1475(sh); 1460(s); 1440(sh);

${ }^{3}$ If crude starting material was used, the methylation product had an extremely strong fragrance due to formation of 2-methoxynaphthalene. 1430(w); 1389(sh); 1370(sh); 1371(m); 1319(m); 1266(s); $1249(\mathrm{~s}) ; 1212(\mathrm{sh}) ; 1177(\mathrm{~m}) ; 1149(\mathrm{~m}) ; 1134(\mathrm{~m}) ; 1089(\mathrm{~s}) ;$ 1064(s); 1050(w); 1020(m); 966(w); 942(sh); 899(s); 868(m); 813(s); 796(sh); 782(m); 757(w); 747(s); 708(m); $678(\mathrm{~m}) \mathrm{cm}^{-1}$.

\subsection{Cyclization}

A mixture of dry, powdered, recrystallized 2,2'. dimethoxy-1,1'-binaphthyl (10 g; 0.033 mole), sodium chloride ( $5 \mathrm{~g})$, and anhydrous aluminum chloride (35 g) was placed in a round-bottomed flask, protected from moisture, and heated at $165{ }^{\circ} \mathrm{C}$ for $90 \mathrm{~min}$. The darkgreen mixture was cooled, and carefully treated with warm $2.5 \mathrm{~N}$ hydrochloric acid containing $2 \mathrm{~g}$ of stannous chloride; after the mixture has been briefly warmed, the black-green solid was filtered off, washed with $2.5 \mathrm{~N}$ hydrochloric acid, and dried over sodium hydroxide in a vacuum desiccator. The yield of crude 1,12-perylenediol was 8-8.5 g (85-91\%). Inspection of the crude product by thin-layer chromatography showed the presence of an appreciable proportion of $1,1^{\prime}$-bi-2-naphthol, indicating that the treatment with aluminum chloride caused some demethylation before cyclization to the perylenediol. When the cyclization reaction was conducted in small batches $(1 \mathrm{~g})$, and the temperature was gradually raised to $165^{\circ} \mathrm{C}$, the amount of side-product decreased somewhat. The crude product was difficult to purify.

In an attempt at purification, a small sample of crude diol was dissolved in warm $p$-dioxane, and the solution was filtered into $6 \mathrm{~N}$ hydrochloric acid containing stannous chloride. The light-gray solid that crystallized out was still impure according to a thinlayer chromatogram with 18:1:1 $(\mathrm{v} / \mathrm{v})$ benzene$N, N$-dimethylformamide-acetic acid. Purification of the diol by column chromatography is also difficult, because of the air oxidation that occurs.

\subsection{Sodium Hydroxide Extraction and Partial Oxidation of 1,12-Perylenediol}

Crude 1,12-perylenediol (5 g; 0.0175 mole) was stirred with 3 percent aqueous sodium hydroxide (1.5 liters) at $55{ }^{\circ} \mathrm{C}$ for $60 \mathrm{~min}$; to prevent oxidation of the diol, small portions ( 4 x $150 \mathrm{mg}$ ) of powdered aluminum-nickel alloy (1:1 by weight) were periodically added to the mixture to avoid foaming due to evolution of hydrogen. The reaction mixture (which showed a strong, green fluorescence) was filtered through a layer of filter paper, and the filtrate was partially oxidized by bubbling air through it at room temperature for 12 to $18 \mathrm{hr}$. The dark-brown solid was filtered off, washed with water, and dried; yield of crude 1,12-perylenequinone, $0.8 \mathrm{~g}(16.1 \%)$. The filtrate was neutralized with concentrated hydrochloric acid, and the dark-brown solid (an additional crop of dione 3 ) was isolated; yield $0.9 \mathrm{~g}$; total yield $1.7 \mathrm{~g}(34.2 \%)$. The second crop contained a considerable proportion of 1,12-perylenediol and other hydroxylated impurities. 


\subsection{Isolation and Purification of 1,12-Perylenequinone (3)}

A suspension of crude dione 3 ( $1 \mathrm{~g} ; 0.0035$ mole) and lead dioxide ( $8 \mathrm{~g}$; $0.033 \mathrm{~mole}$ ) in $200 \mathrm{ml}$ of dry benzene was refluxed for $2.5 \mathrm{hr}$, and filtered while hot. The solid was again refluxed with $150 \mathrm{ml}$ of benzene, and the brown-red filtrates were combined and concentrated to about $120 \mathrm{ml}$. Thin-layer chromatography on silica gel with 18:1:1 (v/v) benzene- $N, N$-dimethylformamide-acetic acid indicated the presence of five components (colored and colorless, but fluorescent). The original filtrate $(120 \mathrm{ml})$ was introduced onto a silica gel column $(5 \times 50 \mathrm{~cm})$ and eluted with $4: 1$ (v/v) benzene-acetic acid (1-1.2 liter; $1 \mathrm{ml}$ per min).

Five zones were successively eluted. The slow-moving, dark-red zone was collected, and evaporated to dryness.

The solid was treated with $150 \mathrm{ml}$ of hot benzene, and the suspension was filtered, the filtrate being run into a stirred slurry of neutral alumina $(75 \mathrm{~g})$ in benzene. The adsorbate with dione 3 was filtered off, and transferred to a column $(3 \times 35 \mathrm{~cm})$, and thoroughly washed with warm benzene until the eluate was free from any fluorescent impurity. The orange-red column was then eluted with $1: 1(\mathrm{v} / \mathrm{v})$ benzene-acetone. The eluate was concentrated to about $3 \mathrm{ml}$, and the solution was filtered. The filtrate was kept for $24 \mathrm{hr}$ at room temperature, giving lustrous, red crystals of 1,12-perylenequinone $(3)$; these were filtered off, washed with benzene, and dried; yield $25 \mathrm{mg}(2.5 \%), \mathrm{mp} 215$ to $217{ }^{\circ} \mathrm{C}$ (darkening at $210{ }^{\circ} \mathrm{C}$ ), lit. mp $287{ }^{\circ} \mathrm{C}$ [16]. The sample was dried at $78{ }^{\circ} \mathrm{C} / 0.05 \mathrm{~mm}$ for $2 \mathrm{hr}$, and analyzed.

Anal. Calcd, for $\mathrm{C}_{20} \mathrm{H}_{10} \mathrm{O}_{2}$ : C, 85.08; H, 3.57. Found: C, 85.20; H, 3.36.

A thin-layer chromatogram (silica gel G, $250 \mu \mathrm{m}$ thick) showed a homogeneous, orange-red spot having a pink-cherry fluorescence; solvent $\mathrm{A}, 60 \mathrm{~min}, R_{f}$ $0.12 \pm 0.02$; solvent $\mathrm{B}, 75 \mathrm{~min}, R_{f} 0.61 \pm 0.02$. A solution of dione $3(10 \mathrm{mg})$ in $p$-dioxane $(1 \mathrm{ml})$ was treated at $40{ }^{\circ} \mathrm{C}$ with $5 \mathrm{ml}$ of 10 percent aqueous sodium hydroxide containing $300 \mathrm{mg}$ of sodium hydrosulfite and $0.25 \mathrm{ml}$ of benzoyl chloride. Concentration and cooling produced greenish-yellow crystals (strong, green fluorescence). The product was dissolved in warm methanol (or methanol-acetone) and the filtered solution was treated with Darco carbon (250 $\mathrm{mg})$. The adsorbate of the product on carbon was extracted with warm benzene; the filtered solution was concentrated to $3 \mathrm{ml}$, and the solution was diluted with ethanol-pentane to turbidity, and kept at room temperature for $24 \mathrm{hr}$. Yellowish crystals $(8 \mathrm{mg})$ were filtered off, and dried at $110{ }^{\circ} \mathrm{C} / 0.05 \mathrm{~mm}$ for $2 \mathrm{hr}$; mp 225 to $226{ }^{\circ} \mathrm{C}$; the product was identical with an authentic sample of 1,12-dibenzoyloxyperylene [16]; $\lambda_{\max }^{\mathrm{MeOH}} 415(\epsilon \sim 6,000)$ and $435 \mathrm{~nm}(\epsilon \sim 7,500)$. $\nu_{\max }^{\mathrm{KCl}} 2958(\mathrm{w}) ; 2873(\mathrm{sh}) ; 1736(\mathrm{~s}) ; 1626(\mathrm{sh}) ; 1592(\mathrm{~m})$; $1497(\mathrm{~m}) ; 1453(\mathrm{~m}) ; 1445(\mathrm{sh}) ; 1373(\mathrm{sh}) ; 1355(\mathrm{~m}) ; 1333(\mathrm{sh})$; 1315(sh); 1255(s); 1218(m); 1205(sh); 1176(m); 1150(sh); 1123(w); 1087(m); 1063(m); 1029(m); 990(sh); 869(m); 826(m); 816(sh); 800(sh); 780(sh); 760(m); 706(s) $\mathrm{cm}^{-1}$.

\section{3,9-Perylenequinone (9)}

\subsection{Discussion}

3,9-Perylenequinone (9) may be prepared by hydrolysis of the corresponding dichloro- or dibromoperylene [19], or by oxidation of $1,2,3,7,8,9$-hexahydro3,9 -perylenequinone with iodine in pyridine [9]. In the present study, quinone 9 was obtained by hydrolysis of a mixture of 3,9- and 3,10-dichloroperylene; preparation of such a mixture was reported by Pongratz and Eichler [20], but the ratio of the isomers was not determined by them, and they made no use of the mixture.

\subsection{Selective Chlorination of Perylene}

Perylene was chlorinated by a slight modification of the procedure of Pongratz and Eichler [20].

To a warm solution of perylene (1) $(2.52 \mathrm{~g} ; 0.01$ mole) in $250 \mathrm{ml}$ of benzene was added $2.8 \mathrm{~g}(0.021$ mole) of sulfuryl chloride, and the solution was refluxed for five hr. The dark-brown reaction mixture was then concentrated to about $70 \mathrm{ml}$ (start of crystallization) and chilled, to give yellow product (750 $\mathrm{mg})$; concentration of the filtrate to about $30 \mathrm{ml}$, followed by cooling, gave an additional crop (150 mg); total, $900 \mathrm{mg}(28 \%)$. Recrystallization of the first crop $(750 \mathrm{mg}$ ) from 40 to $45 \mathrm{ml}$ of warm toluene gave lustrous, golden plates, $500 \mathrm{mg}, \mathrm{mp} 238$ to $241{ }^{\circ} \mathrm{C}$; lit. $\mathrm{mp}$ 242 to $280{ }^{\circ} \mathrm{C}[20]$.

\subsection{Hydrolysis and Separation of 3,9- From 3,10-Perylenequinone}

Recrystallized dichloroperylene mixture (300 mg; 0.093 mole) and $15 \mathrm{ml}$ of concentrated sulfuric acid in a test tube was heated in an aluminum block at 165 to $170{ }^{\circ} \mathrm{C}$ (beginning at $150^{\circ} \mathrm{C}$ ) for $5 \mathrm{hr}$; the dark reaction mixture was cooled, and decomposed with ice water to give a lustrous graphite-like solid, consisting of a mixture of 3,9 - and 3,10-perylenequinones; yield, $250 \mathrm{mg}(95 \%)$. Direct recrystallization of this mixture from $4: 1(\mathrm{v} / \mathrm{v}) \quad N, N$-dimethylformamide-acetic acid, gave a mixture containing 3,10-perylenequinone in high proportion; the red filtrate contained an appreciable amount of 3,9-perylenequinone.

The crude quinone mixture $(150 \mathrm{mg})$ was separated with difficulty on a column of silica gel with glacial acetic acid as the eluant by the procedure given in section 3.2. The rates of migration of 3,9- and 3,10perylenequinones in acetic acid (or other solvents tried) were so close that chromatographic separation had to be repeated three times. Concentration of the eluates yielded $32 \mathrm{mg}$ of 3,9-perylenequinone and about $98 \mathrm{mg}$ of 3,10-perylenequinone, corresponding to an approximate weight ratio of $3: 1$. For analysis, quinone 9 was recrystallized from hot, glacial acetic acid, to give dark-purple needles, mp 372 to $375{ }^{\circ} \mathrm{C}$ (dec.) lit. $\mathrm{mp} 350{ }^{\circ} \mathrm{C}$ (dec.) [9†. 
A thin-layer chromatogram (silica gel G, $250 \mu \mathrm{m}$ thick, $75 \mathrm{~min}$ ) of 3,9-perylenequinone (solvent B), showed a dark-purple spot (light-pink fluorescence) $R_{F} 0.63 \pm 0.03$, as compared to a yellow spot for 3,10 perylenequinone, $R_{f} 0.65 \pm 0.02$.

The best way to distinguish between 3,9- and 3,10 -perylenequinone is by means of their characteristic visible spectra in $N, N$-dimethylformamide. In this solvent, 3,10-perylenequinone shows peaks at 353,395 , and $415 \mathrm{~nm}$, whereas 3,9-perylenequinone shows peaks at 429,523 , and $566 \mathrm{~nm}$; quinone 2 shows no absorption above $415 \mathrm{~nm}$.

The infrared absorption spectrum of 9 shows the following major absorption bands: $\nu_{\max }^{\mathrm{KCl}} 2912(\mathrm{w})$; $1658(\mathrm{~s}) ; 1600(\mathrm{~m}) ; 1448(\mathrm{ml}) ; 1391(\mathrm{~m}) ; 1350(\mathrm{~m}) ; 1301(\mathrm{~m})$; $1268(\mathrm{~m}) ; 1208(\mathrm{~m}) ; 1187(\mathrm{~m}) ; 1142(\mathrm{~m}) ; 1100(\mathrm{~m}) ; 834(\mathrm{~m})$; $741(\mathrm{w}) ; 705(\mathrm{w}) \mathrm{cm}^{-1}$.

\section{Spectrophotometric Measurements}

\subsection{Apparatus}

The infrared spectra were recorded in potassium chloride pellets with a Perkin-Elmer Infracord Model 137 (see footnote 2) and a Model 257 grating spectrophotometer (see footnote 2), which were calibrated against a polystyrene standard or against the Nujol (see footnote 2) band at $2861 \mathrm{~cm}^{-1}$. Ultraviolet and visible spectra were recorded with a Beckman DK-2 spectrophotometer.

\subsection{Discussion of Spectra}

The infrared absorption spectra of polycyclic, aromatic carboxylic anhydrides show a characteristic doublet in the carbonyl absorption region, namely at 1776 and $1742 \mathrm{~cm}^{-1}$ and at 1779 and $1736 \mathrm{~cm}^{-1}$, and this doublet is shown by compounds 6 and 8 . This split of the anhydride carbonyl band into a doublet has been observed for other acid anhydrides $[6,21]$, but the doubling of the carbonyl band in nonpolycyclic, aromatic acid anhydrides appears at somewhat longer wavelength (1865 to $1761 \mathrm{~cm}^{-1}$ ) [22, pp. 127-128].

It may be noted, however, that at least three recrystallizations of compound 7 from hot acetic anhydride were necessary to convert some $\mathrm{C}=\mathrm{O}$ absorption at $1697 \mathrm{~cm}^{-1}$ (due to the free carboxyl group) into the anhydride doublet.

The carbonyl absorption of compound 9 is found at $1689 \mathrm{~cm}^{-1}$, which is normal for aromatic acids [22, p. 162]. The infrared absorption spectra of 3,9-, 3,10-, and 1,12-perylenequinones show carbonyl absorption in the region of 1667 to $1613 \mathrm{~cm}^{-1}$, typical of polycyclic, aromatic quinones [6;22, p. 151]. A transparent region is found between 1111 and $909 \mathrm{~cm}^{-1}$ for 3,9- and 3,10perylenequinones, resembling those observed for the (para) 1,6- and 1,8-pyrenedione [6]; on the other hand, moderate to strong absorption bands are observed for 1,12-perylenequinone in the same region (1111 to $909 \mathrm{~cm}^{-1}$ ), resembling the (ortho) 4,5-pyrenedione [6].

The infrared spectrum of $\mathbf{4}$ shows a strong hydroxyl group absorption at $3333 \mathrm{~cm}^{-1}$, and aromatic quinone bands at 1642 and $1615 \mathrm{~cm}^{-1}$. The spectrum of 5 shows a very weak hydroxyl group absorption, typical of a chelated structure [22, p. 107]; the spectrum also shows a hydrogen-bonded carbonyl absorption at $1638 \mathrm{~cm}^{-1}$ $[22$, p. 144]; moreover, compound $\mathbf{5}$ shows all of the chemical reactions of the chelated hydroxyl group, similar to that described for streptovaricin [23]. However, all attempts failed to confirm a chelate ringstructure for $\mathbf{5}$ by $\mathrm{nmr}$ spectroscopy, because of the insolubility of $\mathbf{5}$ in $N, N$-dimethylformamide, methyl sulfoxide, and other solvents, even at elevated temperature.

This work was supported, in part, by the Division of Air Pollution, Public Health Service, U.S. Department of Health, Education, and Welfare.

The author expresses his appreciation to R. Schaffer and H. S. Isbell for their encouragement, and particular appreciation to R. S. Tipson for many valuable suggestions.

\section{References}

[1] I. Y. Postovskii and N. P. Bednyagina, J. Gen. Chem. U.S.S.R. 1, 2919 (1937).

[2] E. Clar, Polycyclic Hydrocarbons, 2, 27 (Academic Press, New York, N.Y., 1964).

[3] E. M. Kosower, Molecular Biochemistry, p. 183 (McGraw-Hill Book Co., New York, N.Y., 1962).

[4] A. Zinke and E. Unterkreuter, Monatsh. 40, 405 (1919).

[5] B. R. Brown and A. R. Todd, J. Chem. Soc. 1954, 1280.

[6] A. J. Fatiadi, J. Chromatog. 20, 319 (1965).

[7] L. F. Fieser and M. Fieser, J. Am. Chem. Soc. 55, 3010 (1933).

[8] A. Zinke and R. Wenger, Monatsh. 55, 52 (1930).

[9] E. Haslam, Tetrahedron 5, 99 (1959).

[10] A. W. Johnson, J. R. Quayle, T. S. Robinson, N. Sheppard, and A. R. Todd, J. Chem. Soc. 1951, 2633.

[11] A. Zinke and R. Wenger, Monatsh. 56, 147 (1930).

[12] A. Zinke, Monatsh. 57, 405 (1931).

[13] A. Zinke, F. Stimler, and E. Reuss, Monatsh. 64, 415 (1934).

[14] A. Zinke, W. Hirsch, and E. Brozek, Monatsh. 5 1, 205 (1929).

[15] A. Calderbank, A. W. Johnson, and A. R. Todd, J. Chem. Soc. 1954, 1285.

[16] A. Zinke and F. Hanselmayer, Monatsh. 45, 231 (1924).

[17] N. Dianin, Ber. 6, 1252 (1873).

[18] E. Ostermayer and J. Rosenhek, Ber. 17, 2453 (1884).

[19] A. Zinke, R. Springer, and H. Schmidt, Ber. 58, 2386 (1925).

[20] A. Pongratz and E. Eichler, Ber. 69, 1292 (1936).

[21] W. G. Dauben and W. W. Epstein, J. Org. Chem. 24, 1595 (1959).

[22] L. J. Bellamy, The Infra-red Spectra of Complex Molecules, 2d ed. (John Wiley \& Sons, Inc., New York, N.Y., 1958).

[23] R. J. Schacht and K. L. Rinehart, Jr., J. Am. Chem. Soc. 89, 2239 (1967).

(Paper 72Al-480) 